\title{
Effectively treating ischemic mitral regurgitation with chordal cutting in combination with ring annuloplasty and left ventricular reshaping approach
}

\author{
Hiroyuki Yamamoto, MD, Yoshifumi Iguro, MD, Ryuzo Sakata, MD, Kenichi Arata, MD, and Goichi Yotsumoto, MD,
} Kagoshima, Japan

I schemic mitral regurgitation (IMR) is a common complication of ischemic heart disease that often leads to an adverse prognosis after myocardial infarction and coronary revascularization. ${ }^{1}$ The present accepted therapy for IMR is to reduce the annular size, thereby making a deep coaptation zone. The efficacy of chordal cutting for IMR was first reported by Messas and associates ${ }^{2,3}$ in 2001. Although this method has been described as a simpler approach to reduce tethering in an experimental study, we thought that cutting a limited number of critically positioned chordae, which restrict leaflet closure, might be an effective surgical modality for repair of IMR in clinical cases. We herein present the case of a patient who was treated with chordal cutting in combination with ring annuloplasty and an overlapping cardiac volume reduction operation, which is a new clinical therapeutic approach for the treatment of IMR.

\section{Clinical Summary}

A 69-year-old man with ischemic cardiomyopathy associated with IMR and atrial fibrillation was admitted to our institute in February 2004. He had previously presented with acute myocardial infarction of the left anterior descending branch in 1992. Percutaneous transluminal coronary angioplasty for the left anterior descending coronary artery has been performed 3 times for restenosis since 1992. Symptoms of both cardiomegaly and congestive heart failure have been progressively worsening since 2000 . The patient was readmitted in November 2003 because of acute heart failure, which he experienced 3 times after the introduction of a $\beta$-blocker. Echocardiography demonstrated an ejection fraction of $26 \%$ with severe-to-moderate mitral regurgitation (MR), a dilated mitral annulus $(49 \times 41 \mathrm{~mm})$, severe hypokinesis or akinesis of the anteroseptal left ventricular (LV) motion, and a characteristic distortion of the base of the anterior mitral leaflet (AML), which was tethered by strut chordae to form a bend, thereby reducing the coapting surface (Figure 1, A). Preoperative coronary angiography

\footnotetext{
From the Department of Thoracic and Cardiovascular Surgery, Kagoshima University, Kagoshima, Japan.

Received for publication Jan 5, 2005; revisions received March 25, 2005; accepted for publication April 1, 2005.

Address for reprints: Hiroyuki Yamamoto, MD, Department of Thoracic and Cardiovascular Surgery, Kagoshima University, 8-35-1 Sakuragaoka, Kagoshima, 890-8520, Japan (E-mail: h-yamamoto@h5.dion.ne.jp).

J Thorac Cardiovasc Surg 2005;130:589-90

$0022-5223 / \$ 30.00$

Copyright $\odot 2005$ by The American Association for Thoracic Surgery

doi:10.1016/j.jtcvs.2005.04.006
}

revealed no progression of coronary arterial stenosis or a restenosis at the stenting site.

The operation was performed on February 23, 2004. During cardiopulmonary bypass under mild hypothermic conditions with antegrade cold cardioplegia, 4 strut chordae, which exert force on the body of the AML near its base, were cut through a left ventriculotomy (Figure 2). Mitral annuloplasty with a 30-mm Carpentier rigid ring was performed for the severe dilated annulus. Next, a left atrial maze operation with cryoablation isolating orifices of the pulmonary veins and an overlapping cardiac volume reduction operation to reduce the increased LV volume caused by ischemic cardiomyopathy were performed.

The patient recovered uneventfully. Postoperative echocardiography demonstrated no MR, no prolapse of the AML in spite of performing strut chordal cutting, and an improved ejection fraction of $50 \%$. Furthermore, the tethering of the AML forming a bend had completely disappeared, and an adequate coapting surface had been obtained (Figure 1, B). The patient was discharged 35 days after the operation. Presently, at 6 months after the operation, the patient is classified as New York Heart Association class II, and echocardiography showed no MR and excellent cardiac function.

\section{Discussion}

Recent studies have confirmed the relation of IMR to the remodeling and distortion of the ischemic left ventricle. A displacement of the papillary muscles tethers the mitral leaflets into the left ventricle and thus restricts the effective closing force at the level of the mitral annulus, which might also be dilated.

The currently accepted repair techniques for IMR most often involve annular reduction with the placement of undersized rigid and semirigid annuloplasty rings. Such annuloplasty reduces the anterior-posterior valve dimension and increases the coapting surface of the leaflets. However, this traditional repair might also lead to increased leaflet tethering because the valve orifice becomes separated from the papillary muscles. The failure rate for this technique alone might be as high as $30 \%$ in patients with functional IMR. ${ }^{4}$ Therefore, a recent editorial suggests that annular reduction cannot recreate adequate leaflet coaptation if one or both leaflets remain extensively apically tethered. ${ }^{5}$

In this case, because echocardiography demonstrated a tethering of the AML by strut chordae, a severely dilatated annulus, and LV dilatation, we attempted to perform chordal cutting with annuloplasty to correct the distortion and annular dilatation at the same time. This combined method is considered to overcome any potential disadvantages of annular reduction caused by the use of annuloplasty rings. 


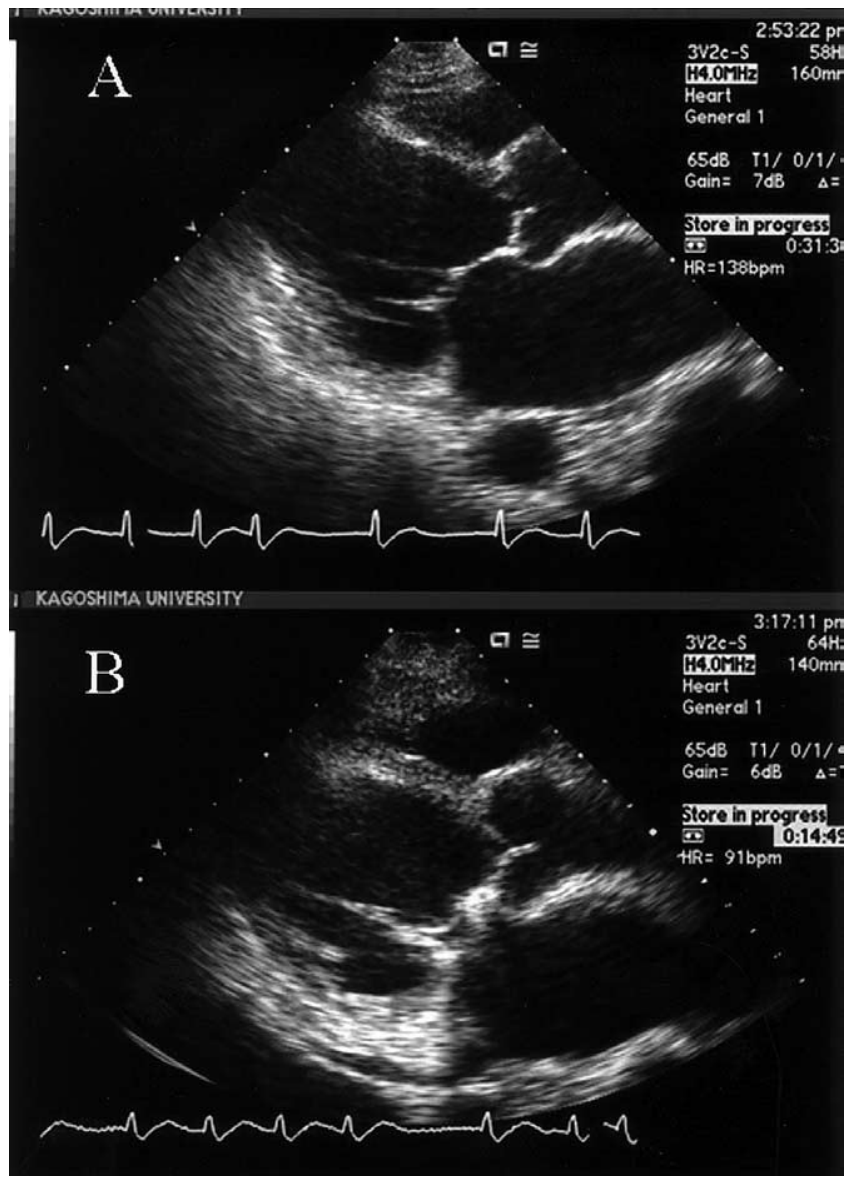

Figure 1. Preoperative echocardiography demonstrated a distortion of the base of the AML, which is tethered by strut chordae to form a bend, thus reducing the coapting surface, a dilatation of mitral annular diameter (A). The postchordal cutting echocardiography demonstrated no prolapse of the $A M L$, an adequate coapting surface, and a complete disappearance of the tethering of the AML (B).

In conclusion, we currently consider chordal cutting to be a simple, safe, and effective surgical modality for patients with IMR because of a tethering of the mitral leaflet. Although the early results in this case have been encouraging, the longitudinal valverelated outcomes are still unknown. As a result, further investigations of this method and long-term follow-up in a large series of patients are mandatory.

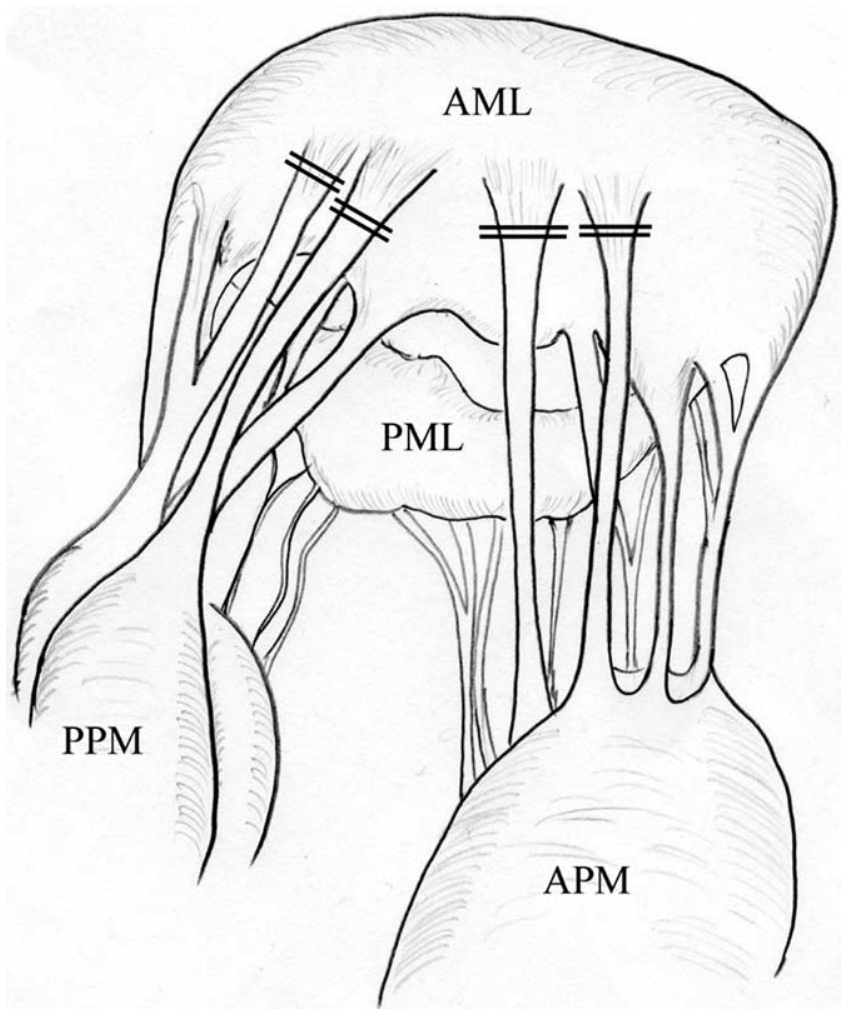

Figure 2. A schematic representation of how the 4 strut chordae were cut through a left ventriculotomy. PML, Posterior mitral leaflet; $A P M$, anterior papillary muscle; $P P M$, posterior papillary muscle; dashed sections, chordal cutting.

\section{References}

1. Grigioni FG, Enriquez-Sarano M, Zehe KJ, Bailey KR, Tajik AJ. Ischemic mitral regurgitation: long-term outcome and prognosis implications with quantitative Doppler assessment. Circulation. 2001;103: 1759-64.

2. Messas E, Guerrero JL, Handschumacher MD, Conrad C, Chow CM, Sullivan S, et al. Chordal cutting: a new therapeutic approach for ischemic mitral regurgitation. Circulation. 2001;104:1958-63.

3. Messas E, Pouzet B, Touchit B, Guerrero JL, Vlahakes GJ, Desnos M, et al. Efficacy of choral cutting to relieve chronic persistent ischemic mitral regurgitation. Circulation. 2003;108(suppl II):II111-5.

4. Tahta SA, Oury JH, Maxwell JM, Hiro SP, Duran CM. Outcome after mitral valve repair for functional ischemic mitral regurgitation. J Heart Valve Dis. 2002;11:11-8.

5. Miller DC. Ischemic mitral regurgitation redux: to repair or to replace? J Thorac Cardiovasc Surg. 2001;122:1059-62. 